\title{
Oil production rate and Recovery factor evaluation for Beierxi
}

\author{
Zhang Jicheng ${ }^{1, a}$, Chen Xinyu ${ }^{1, b}$, Lv Bingyu ${ }^{1, c}$, Feng Yang ${ }^{1, d}$ \\ ${ }^{1}$ College of Petroleum Engineering, Northeast Petroleum University Daqing, Heilongjiang, P.R. \\ China, 163318 \\ azhangjc777@163.com, ${ }^{b}$ chen_xinyu163@163.com, \\ cdaqinglby@163.com, ${ }^{d} 13069659713 @ 163 . c o m$.
}

\begin{abstract}
Keywords: Oil production rate evaluation, Recovery factor prediction, Effect of water flooding Abstract: The trend of development index of oilfield which mainly is decided by two aspects: On the one hand, it depends on geologic condition. On the other hand, it depends on well pattern arrangement. In recent years, with well spacing density gradually adjusted and improved for Beierxi of Daqing oilfield, thus oil production rate has enhanced. At the same time, it faced with the problem of hard to stabilizing oil production rate and to control water cut. For further developing oilfield reasonably and effectively, potential-tapping measurements which are appeal to actual reservoir are proposed. It is necessary to evaluate oil production rate, predict recovery factor and scientific evaluation for effect of water flooding. On the basis of referring to a number of actual field of Daqing, and by analyzing the trend of development index, oil production rate, decline rate, recovery factor, water cut, water cut rising rate, thereby effect of water flooding is multifaceted evaluation. To analyze formation adaptability evaluation and well pattern adaptability evaluation, which combine with well pattern density, water drive reserves and recoverable reserves production degree simultaneously. Thus clear main control factors that affect influence development, and it provides a scientific basis for further adjusting and improving development for oilfield.
\end{abstract}

\section{Introduction}

In 1955, Guthrie ${ }^{[1]}$ American et al. predicted formula of water flooding recoverable reserves of water flood oilfield with multiple regression analysis. In 1958, Wright ${ }^{[2]}$ deduced Semi log linear relationship between water oil ratio and cumulative oil production rate on this basis. Matthew ${ }^{[3]}$ concluded Semilog arithmic linear relationship between water oil ratio and cumulative oil production rate, later generations is based on two types of water flooding characteristic curve as a calculate method of the recoverable reserves of oil field water flooding. In China, Chen Yuanqian ${ }^{[3]}$ concluded the method of oil production rate and recovery factor on different development stages by induced and selected development experience of recoverable reserves. Zhang Rui ${ }^{[4]}$ proposed a method of predicted water flooding effectiveness, who used oil production rate curve and dimensionless injected evaluation. Zan Lixin ${ }^{[5]}$ concluded that the calculation method of water flooding index standard curve and water storage percentage, and he was based on water storage percentage and water flooding index. Yu Qitai ${ }^{[6]}$ deduced that formula for production decline of water flooding oilfield under continuously liquid production. Meanwhile, he set up the connection between water drive characteristic curve and production decline curve. Lemouzy ${ }^{[7]}$ and Jones ${ }^{[8]}$ simulated and evaluated the effective oilfield development with numerical simulation evaluation method. Dunn ${ }^{[9]}$ et al. who make non dimensional curve simulator to evaluate the index of predict water flooding recovery factor. Wang Guoxian ${ }^{[10]}$ et al. to analyze oilfield development by water flooding, and they were applying instantaneous water cut-recovery percent ratio and cumulative water cut-recovery percent ratio. Wang Wenhuan ${ }^{[11]}$ et al. put forward that the evaluation of compare the actual degree of reserve recovery factor, ideal coefficient and water relation curve with theoretical degree of reserve recovery factor and water curve on development efficiency for oilfield. Feng Qihong ${ }^{[12]}$ et al. concluded a curve was based on water flooding correction to calculate water cut rate reservoir and degree of reserve recovery factor, water storage percentage 
and degree of reserve recovery factor, and they made the curve as a theoretical curve which evaluate an efficiency of oilfield development by water flooding. In recent years, Zhang Jinqing ${ }^{[13]}$ et al. concluded that water cut increase rate of water flooding has trend properties and their affecting factors which were based on oil-water relative permeability curves and fractional flow equation. Yan Qinghui ${ }^{[14]}$ et al. were adaptability research that four kinds of water flooding commonly characteristic curve by actual oilfield, water cut increase rate and change for water content with water flooding rule curve. Wang Xiaolin ${ }^{[15]}$ interrelated a new of water flooding characteristic curve which based on the change of oil and water relative permeability with water saturation at extra high water-cut stage. Previous made some research about evaluated and predicted oil production rate, but different evaluation method not widely applies during practical guidance oil production rate development oilfield because different evaluation index has complexity and limitations. In this paper, on the basis of referring to a number of situations of development and deployment at Beierxi area, and evaluate formation structure, well pattern arrangement and effective measures by some evaluation methods such as dimensionless productivity index, dimensionless liquid production index and natural decline rate. This paper predicted ultimately recovery factor by water flooding characteristic curve and water storage percentage theoretical chart method, and evaluated.

\section{Evaluation of production rate}

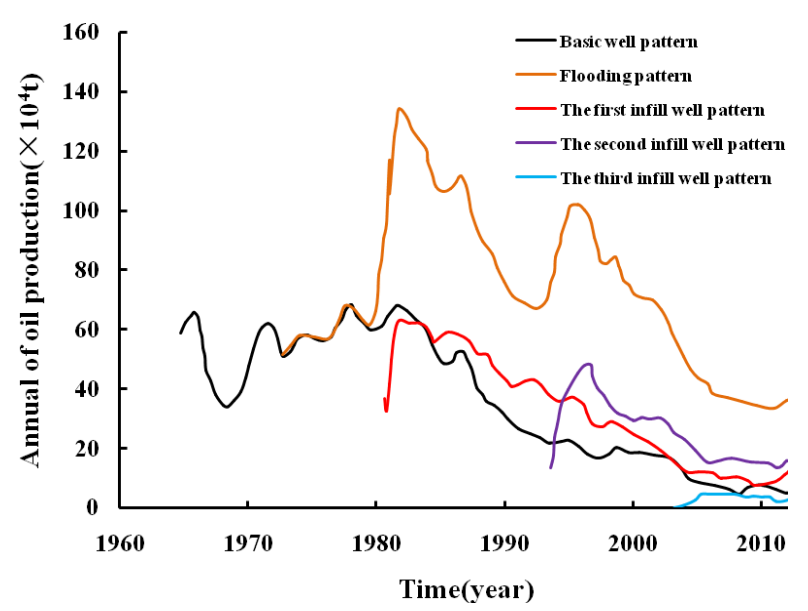

Fig.1 Variation curve of water drive well pattern annual of oil production rate at Beierxi section

Evaluation of oil production rate. From the figure, oil production rate of Beierxi is relatively low at the initial stage of production. In 1964, oil production rate is gradually increasing because main reservoir increased of basic well pattern at SP area. In 1967, annual oil production rate seems to peak and annual fluid production reaches to 64.85 million tons, but in 1969, oil production rate decreased to 35.08 million tons. Later, oil field got into stably production stage gradually. In 1981, high-permeable formation and low-permeable formation increase the first infill well pattern at PII section. Fortunately, annual oil production rate has suddenly increased. In 1982, annual oil production rate reached 133.25 million tons. In 1996, annual oil production rate seems to have a peak, and it reached 103.20 million tons. In 1994, oilfield has increased the second infill drilling program at SA and PII section. Unfortunately, annual oil production rate has suddenly drop later put on production of infill well pattern. In 2004, annual oil production rate has gradually increasing because it has increased infill the third infill drilling programs. 


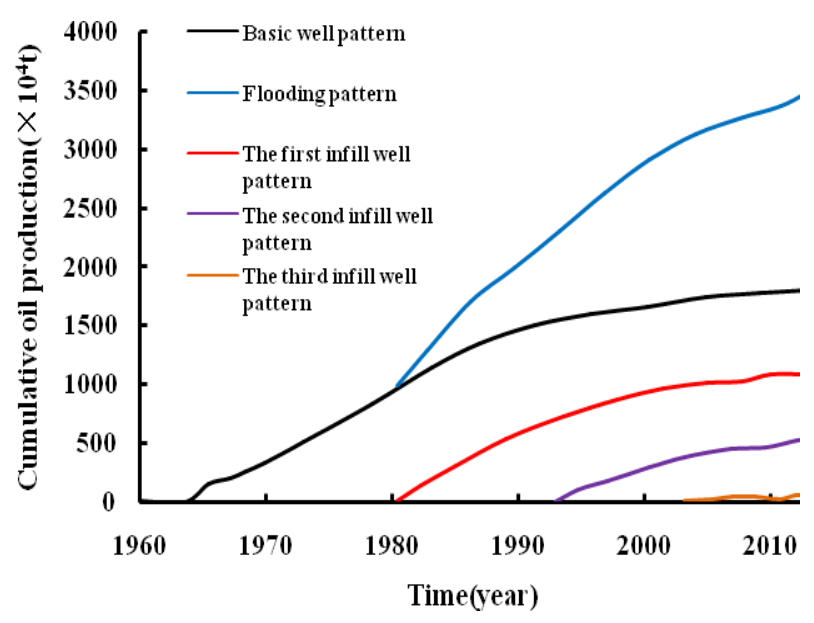

Fig. 2 Variation of cumulative oil production rate well pattern at Beierxi area

It can be seen from figure 4 that cumulative oil production rate can enhance with age. Cumulative oil production rate rapidly increasing because of the first infill well pattern put into production. At present, cumulative oil production rate reached 3435.41 million tons.

Evaluation for dimensionless liquid production index and dimensionless productivity index.

The change of oil well productivity with water flooding development reservoir, liquid production index and productivity index are related to reservoir physical property, fluid property and production conditions. In different conditions, liquid production capacity and oil production rate capacity of well may vary greatly, but the gap of between with liquid production capacity and oil production rate capacity of well has some regularity. Theoretical calculation which based on oil-water relative permeability curves concluded change of liquid production capacity and oil production rate capacity of well with water contents. According Darcy's law, it express a change of dimensionless fluid index and dimensionless productivity index with water contents.

According to the formula:

$$
\begin{aligned}
& J_{\mathrm{o}}=K_{\mathrm{ro}}\left(s_{\mathrm{w}}\right) / K_{\mathrm{ro}}\left(s_{\mathrm{wc}}\right) \\
& J_{\mathrm{L}}=K_{\mathrm{ro}}+K_{\mathrm{rw}} \times \frac{\mu_{\mathrm{o}}}{\mu_{\mathrm{w}}} \\
& f_{\mathrm{w}}=\frac{1}{1+\left(\mu_{\mathrm{w}} / \mu_{\mathrm{o}}\right)\left(k_{\mathrm{ro}} / k_{\mathrm{rw}}\right)}
\end{aligned}
$$

Can be obtained from the above equation:

$$
\begin{aligned}
& J_{\mathrm{o}}=\frac{\left(\frac{1}{f_{\mathrm{w}}}-1\right) \times \frac{\mu_{\mathrm{w}}}{\mu_{\mathrm{o}}} \times K_{\mathrm{rw}}}{K_{\mathrm{ro}}\left(S_{\mathrm{wc}}\right)} \\
& J_{\mathrm{L}}=\left(\frac{1}{f_{\mathrm{w}}}-1\right) \times \frac{K_{\mathrm{rw}}}{K_{\mathrm{ro}}}+K_{\mathrm{ro}}
\end{aligned}
$$

Where: $\mathrm{J}_{\mathrm{o}}$ is Dimensionless productivity index;

$\mathrm{J}_{\mathrm{L}}$ is Dimensionless fluid productivity index;

$\mathrm{K}_{\mathrm{ro}}$ is The oil phase relative permeability under different water saturation;

$\mathrm{K}_{\mathrm{rw}}$ is The water phase relative permeability under different water saturation;

$\mathrm{f}_{\mathrm{w}}$ is Water cut rate;

$\mu_{\mathrm{o}} / \mu_{\mathrm{w}}$ is Oil/water viscosity ratio;

$S_{\mathrm{w}}$ is Water saturation. 


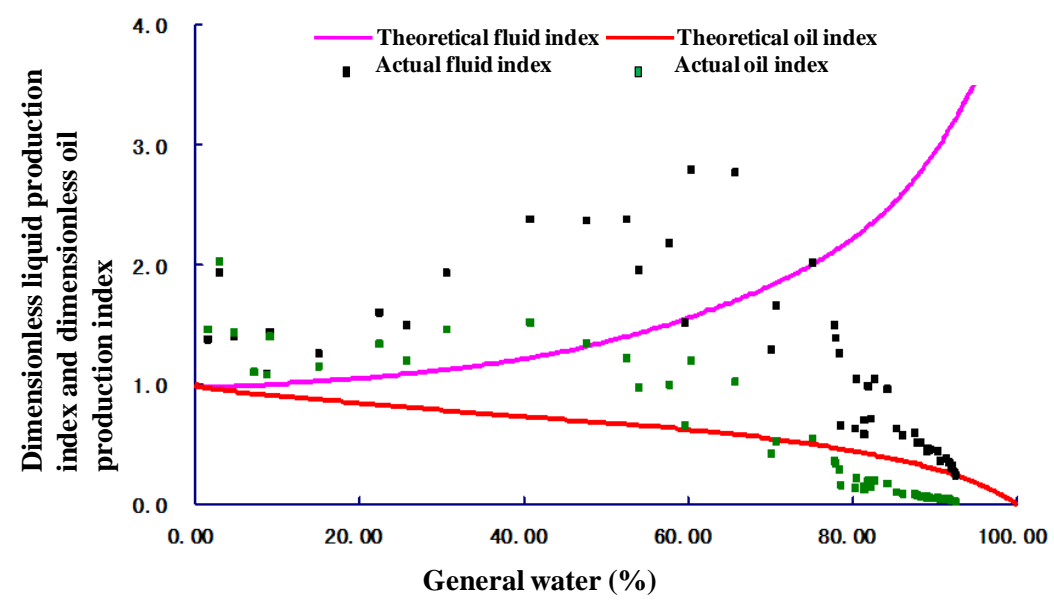

Fig. 3 Correlation curve for between actual value and theoretical value of fluid index and oil productivity index at Beierxi area

Due to the curve of dimensionless oil production rate, dimensionless liquid production and change law of water content, the main achievement of this dissertation is as follows: Increase oil production rate has different effects by lifting fluid measurement at different water-cut stages. With water-cut rate rising, there is a slight increase at dimensionless fluid productivity index, and dimensionless productivity index less decreased. At this time, oil production rate enhanced significantly by lifting fluid measure. When water-cut rate reached $80 \%$, dimensionless fluid productivity index largely and rapidly increasing, but dimensionless productivity index significantly decrease. When predict water cut rate reached $80 \%$, dimensionless fluid productivity index reached 3.8 , dimensionless productivity index reached 0.1 , thus research area has the lifting fluid potential. But incremental oil has slight increase because enhance fluid withdrawal rate measure after high water-cut stages. Due to correlation curve for change law of water content between actual valve and theoretical value of dimensionless fluid productivity index and dimensionless productivity index, dimensionless fluid productivity index and dimensionless productivity index are lower than theoretical value after water -cut rate reached $60 \%$ at Beierxi area. At present, water-cut rate has reached more than 90\%. Dimensionless productivity index reached 0.02. Dimensionless fluid productivity index reached 0.26 . At the present stage incremental oil has a slight increase because enhanced fluid withdrawal rate measurement, and to enhance production should be taken measures of bed set well patterns structured adjust.

\section{Decreasing evaluation}

The evaluation of Natural decline rate. Natural decline rate of oil production rate defined as oil production rate decreasing percentage in unit time.

The design formula is:

$$
N_{\mathrm{D}}=\frac{P_{\mathrm{a}}-P_{\mathrm{b}}-P_{\mathrm{c}}}{P_{\mathrm{d}}}
$$

Where: $\mathrm{N}_{\mathrm{D}}$ is natural decline rate;

$\mathrm{P}_{\mathrm{a}}$ is daily average oil production rate of old well by the end of this year;

$\mathrm{P}_{\mathrm{b}}$ is measure daily enhance oil production rate of old well by this year;

$\mathrm{P}_{\mathrm{c}}$ is daily average enhance oil production rate of old well by the end of last year;

$\mathrm{P}_{\mathrm{d}}$ is daily average oil production rate of old well by the end of last year.

The old well was production well before the end of last year. Daily oil production rate increased measurements are old well daily increase oil production rate quantity. Natural decline rate reveals that all production wells the change of law oil production rate if not taken measures. If the value is negative, oil production rate decreased. Else, oil production rate not decreased. This is an important criterion which inspects whether stable production and arranges workload of measurement. 


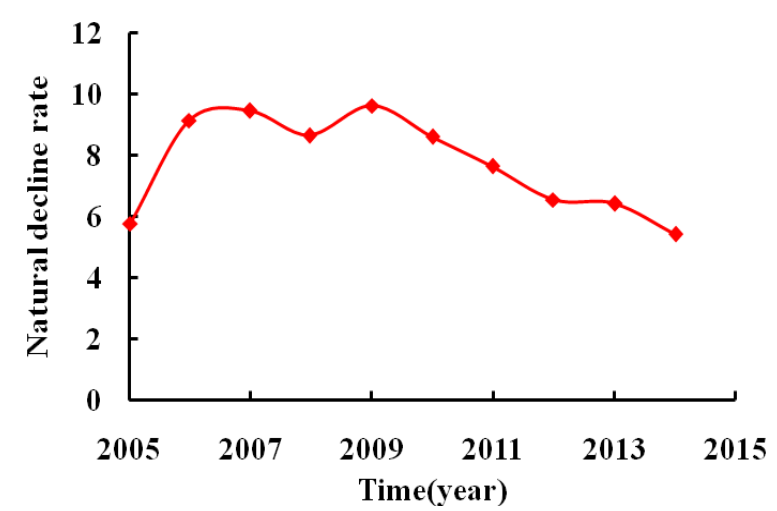

Fig. 4 Variation of natural decline rate at Beierxi area

It can be seen from figure 4 that natural decline rate decreasing at Beierxi area since 2005. It reveals that good effect of stable production recently.

Determining the decline type of oil production rate. When the oilfield turns into the mid later development phase, production decline is inevitable. Different reservoirs have different types of decrease law of oil production rate, because of some factors such as geological features, fluid properties, well pattern types and control conditions and so on. Decrease law broken down into three types: exponential decline, hyperbolic decline pattern and harmonic decline. In this paper, the method of determining the decrease type is the graphic method.

Table 1 Decline types and formulas of decline law

\begin{tabular}{c|c|c|c}
\hline Decline types & $\begin{array}{c}\text { exponential } \\
\text { decline }\end{array}$ & $\begin{array}{c}\text { hyperbolic decline } \\
\text { pattern }\end{array}$ & harmonic decline. \\
\hline Decline index & $\mathrm{n}=0$ & $0<\mathrm{n}<1$ & $\mathrm{n}=1$ \\
\hline Decline rate & $D=D_{\mathrm{i}}=$ Constant & $D=D_{\mathrm{i}}\left(1+n D_{\mathrm{i}} t\right)^{-1}$ & $D=D_{\mathrm{i}}\left(1+D_{\mathrm{i}} t\right)^{-1}$ \\
\hline Oil production rate and time & $Q=Q_{\mathrm{i}} e^{-\mathrm{Dt}}$ & $Q=Q_{\mathrm{i}}\left(1+n D_{\mathrm{i}} t\right)^{-1 / \mathrm{n}}$ & $Q=Q_{\mathrm{i}}\left(1+D_{\mathrm{i}} t\right)^{-1}$ \\
\hline $\begin{array}{c}\text { Oil production rate and } \\
\text { cumulative oil production rate }\end{array}$ & $\begin{array}{c}Q=Q_{\mathrm{i}}-D Q_{\mathrm{p}} \\
N_{\mathrm{p}}=\frac{Q_{\mathrm{i}}-Q}{D_{\mathrm{i}}}\end{array}$ & $\left(\frac{1}{Q}\right)^{\mathrm{n}}=\left(\frac{1}{Q_{i}}\right)^{\mathrm{n}}+\frac{n D_{\mathrm{i}}}{Q_{\mathrm{i}}} t$ & $\frac{1}{Q}=\frac{1}{Q_{\mathrm{i}}}+\frac{D_{\mathrm{i}}}{Q_{\mathrm{i}}} t$ \\
\hline
\end{tabular}

Graphic method is decline type which is based on the linear relationship of oil production rate and time or oil production rate and cumulative oil production rate. In general, if the relation between oil production rate $\mathrm{Q}$ and time $\mathrm{T}$ was linear under semi log coordination, that is to say, if the relation between oil production rate $Q$ and cumulative oil production rate $N_{p}$ was linear in rectangular coordinates, else if, draw a curve of oil production rate $Q$ and cumulative oil production rate under semi log coordination. If the curve is a linear relation, the type is harmonic decline. Else if, the type is hyperbolic decline.

If the type is an exponential decline, according to the formula $\lg Q=\mathrm{a}-\mathrm{b} t$ to arrive at decline rate $\mathrm{D}=2.303 \mathrm{~b}$. If the type is a harmonic decline, according to the formula $\lg Q=\mathrm{a}-\mathrm{b} N_{\mathrm{p}}$ to arrive at initial decline rate $D_{\mathrm{i}}=\mathrm{b} \times 10^{\mathrm{a}} / 2.303$, come $D=D_{\mathrm{i}}\left(1+D_{\mathrm{i}} t\right)^{-1}$. 


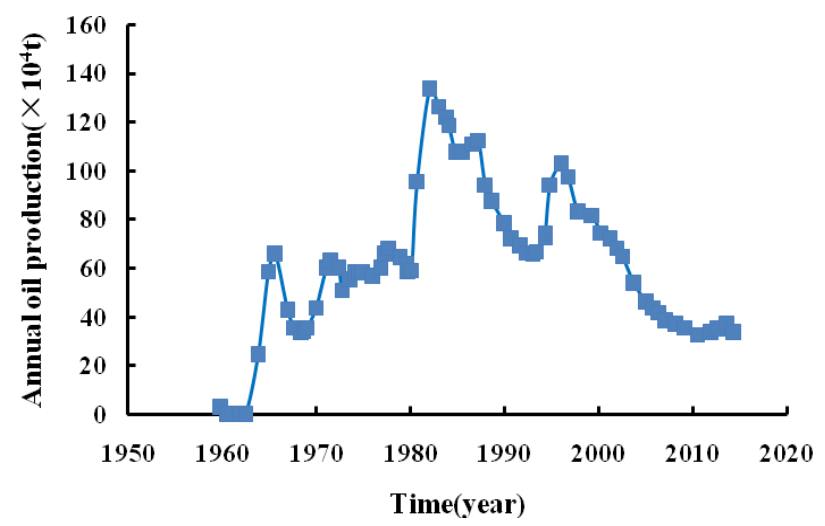

Fig.5 The curve of Q-t by flooding pattern at Beierxi area

In this paper, the year of 1995 is selected as the starting point stable decline time, in other words, the starting point is $\mathrm{t}=0$. And draw the curve of between oil production rate and time, in addition, regression this formula.

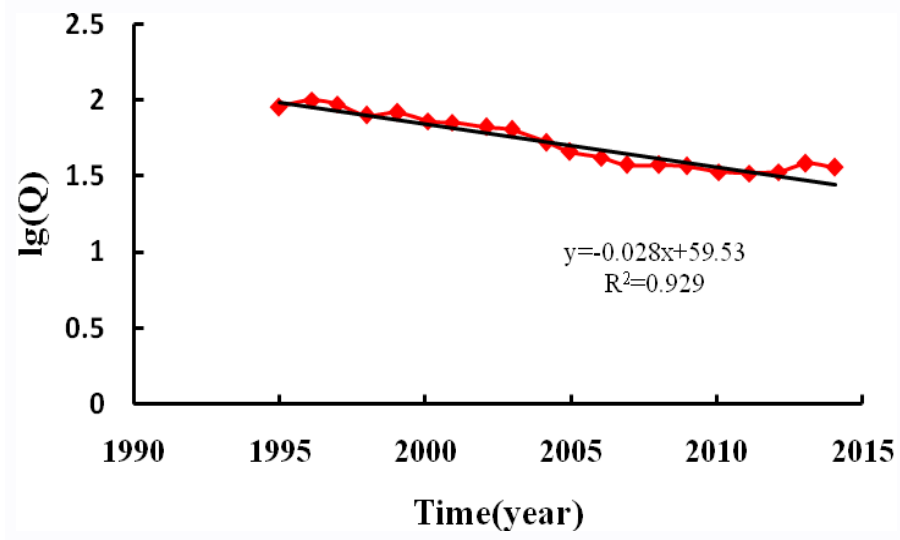

Fig.6 Curve of lgQ-t by flooding pattern at Beierxi

It can be seen from figure 6 that the linear relation between time and oil production rate are better. It reveals the type is an exponential decline, and $b=0.028, D=0.303 b=0.064$. Decreasing coefficient is 0.064 , decline grow rapidly.

\section{Evaluation for recovery factor}

When a reservoir by natural water drive or water flooding has all-round development and entered stabilized production stage, in addition, water-cut rate reached a high degree and gradual rise. Among dynamic indicator such as cumulative oil production rate, cumulative water production, cumulative fluid production and water-cut rate (water/oil) have obviously linear relationship in different coordinate system. In general, this type of curve is a water flooding characteristic curve. Using a logarithmic scale for cumulative water production reservoir $\mathrm{Wp}$ and using a normal coordinate for cumulative oil production rate reservoir $\mathrm{Np}$ under semi log coordination. Drawn the relationship curve of them and a straight-line segment was seen in this curve. The fundamental relationship is:

$$
\lg W_{\mathrm{p}}=B N_{\mathrm{p}}+A
$$

Where: $\mathrm{Wp}$ is cumulative water production $(\times 106)$.

This method called displacement characteristics method actually work. At present, People use water flooding characteristic curve, oilfield development efficiency and predict dynamic indicator reservoir.

The formula can be transformed into:

$$
N_{\mathrm{p}}=a\left(\lg W_{\mathrm{p}}-\lg b\right)
$$

The logarithmic value of between oil production rate and water production are the physical 
interpretation of $b$. The value mainly reflects factors which are geologic and develop program arrangement. The value of $\mathrm{b}$ is smaller, development efficiency the better. The different log kow between oil production rate and water production are the physical interpretation of a. The value mainly reflects the value of $b$, the time of water flooding and oil-water viscosity spread. The water-free recovery factor becomes bigger and oil/water viscosity ratio becomes smaller, the value of a becomes smaller. This means that its effects are better in the initial stage of reservoir development.

Based on a characteristic curve of water flooding to predict ultimate recovery factor. Employing the current widely used the concept of limit water-cut or limited water-oil ratio. If exceeded this limit, oilfield lose real value to develop, while reach this limit, degree of reserve recovery factor is precisely what ultimate recovery factor. In general, limit water cut percentage is $98 \%$ or limit water-oil ratio is 49 . The value of predict recovery factor by empirical method compare with other methods will cater for practical production.

The formula can be transformed into:

$$
N_{\mathrm{p}}=a\left(\lg \frac{a F_{\mathrm{wo}}}{2.3}-\lg b\right)
$$

Bringing limit water-oil ratio Fwo=49 into equation, come:

$$
N_{\text {pmax }}=a(\lg 21.3 a-\lg b)
$$

So,

$$
R_{\max }=\frac{N_{\text {pmax }}}{N}=\frac{a}{N}(\lg 21.3 a-\lg b)
$$

Where: $\mathrm{N}$ is geologic reserve.

And the biggest degree of reserve recovery factor is precisely ultimate recovery factor.

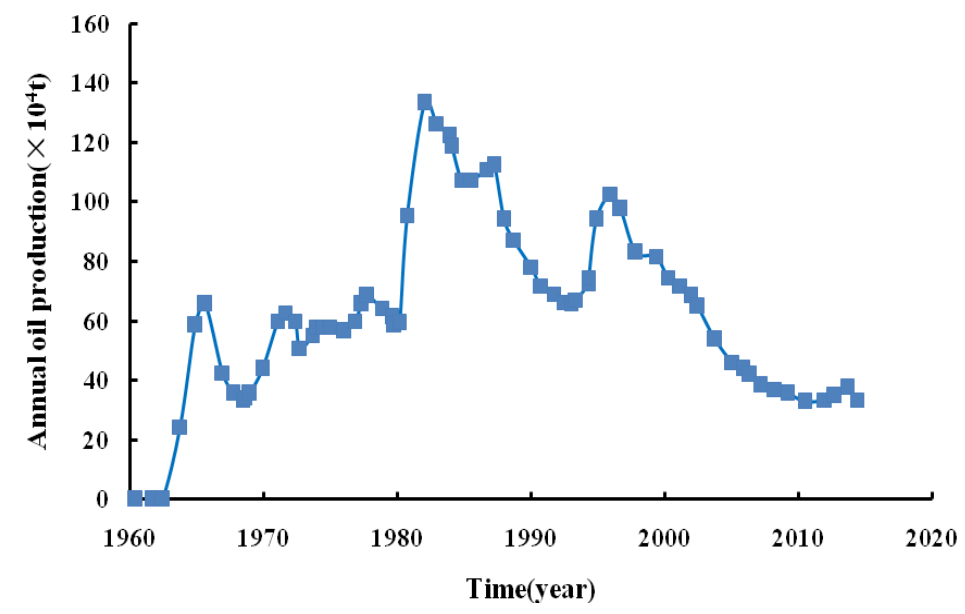

Fig.7 Variation of annual oil production rate of flooding pattern at Beierxi area

Predicting ultimate recovery factor by water flooding characteristic curve. This is semi-log relation curve between cumulative oil production rate and cumulative water production. 


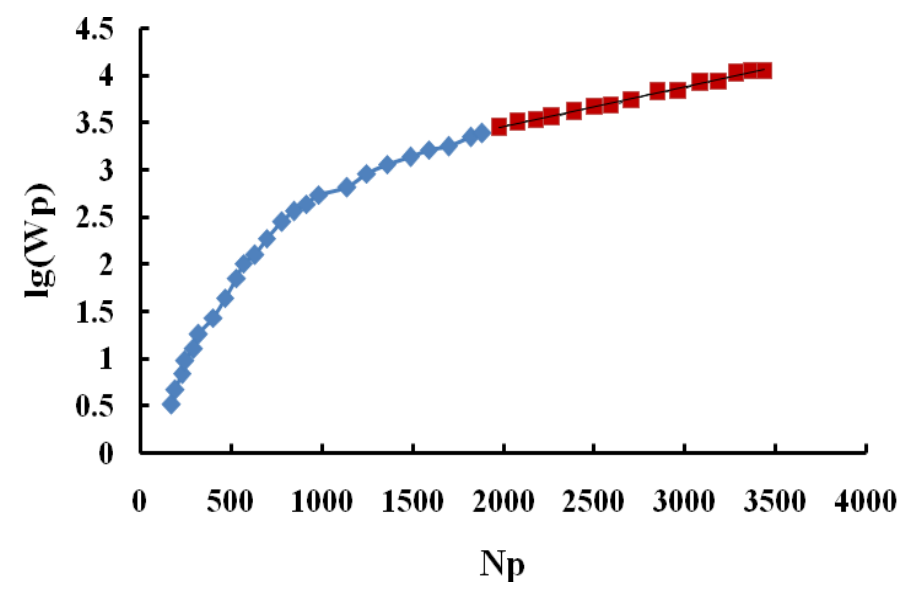

Fig. 8 Water flooding characteristic curve of flooding pattern at Beierxi area

The paper selects 2000 when annual oil production rate slightly decreasing as the starting point of fitting a straight line. It can be seen from appropriate curve that the value of slope is 0.000477873 and the value of offset is 2.830928915 , so

$$
\begin{aligned}
& \lg W_{\mathrm{p}}=0.000477873 N_{\mathrm{p}}+2.830928915 \\
& a=\frac{1}{B}=2092.60707, b=10^{\mathrm{A}}=677.5306, \mathrm{~N}=7953.93 \times 104 \mathrm{t}, \quad R_{\max }=47.83 \% .
\end{aligned}
$$

Calculating the reached the limit of recovery factor degree is the ultimate recovery factor of oilfield.

Predicting ultimate production by water storage percentage theoretical chart method. The underground water storage percentage is the ratio between underground water existence and total injection.

$$
E_{\mathrm{s}}=\frac{W_{\mathrm{i}}-W_{\mathrm{p}}}{W_{\mathrm{i}}}=1-\frac{W_{\mathrm{p}}}{W_{\mathrm{i}}}
$$

Due to water flooding characteristic curve:

$$
\begin{aligned}
& \frac{W_{\mathrm{i}}}{N_{\mathrm{p}}}=e^{\left(a_{1}+b_{1} R\right)} \\
& \frac{W_{\mathrm{p}}}{N_{\mathrm{p}}}=e^{\left(a_{2}+b_{2} R\right)}
\end{aligned}
$$

Bringing this formula into equation, come:

$$
\ln \left(1-E_{\mathrm{i}}\right)=A_{\mathrm{s}}+B_{\mathrm{s}} R
$$

Or

$$
\ln \left(\frac{W_{\mathrm{p}}}{W_{\mathrm{i}}}\right)=A_{\mathrm{s}}+B_{\mathrm{s}} R
$$

Where: $\left(\frac{W_{\mathrm{p}}}{W_{\mathrm{i}}}\right)$ is drainage percent and decimals;

$\mathrm{R}$ is degree of reserve recovery factor, its unit is \%;

$\mathrm{E}_{\mathrm{i}}$ is water storage percentage;

$\mathrm{W}_{\mathrm{p}}$ is cumulative water production, its unit is million tons;

$\mathrm{W}_{\mathrm{i}}$ is cumulative water injection rate, its unit is million tons;

$\mathrm{A}_{\mathrm{s}}$ and $\mathrm{B}_{\mathrm{s}}$ is statistical constant.

In this paper, different water storage percentage $\left(E_{s}\right)$ of degree of reserve recovery factor $(R)$ was 
deduced. The value is closely related water flooding recovery factor, and statistical constant ( $\mathrm{A}_{\mathrm{s}}$ and $B_{s}$ ) express as function of $E_{R}, D_{s}$ is statistical constant of water storage percentage.

When the value of $\frac{W_{\mathrm{p}}}{W_{\mathrm{i}}}$ approaches $1, \mathrm{~B}_{\mathrm{s}}$ can be express as:

$$
\begin{aligned}
& B_{\mathrm{s}}=\frac{D_{\mathrm{s}}}{E_{\mathrm{R}}} \\
& A_{\mathrm{s}}=\ln \left(1-E_{\mathrm{s}}\right)-B_{\mathrm{s}} R=\ln \left(1-E_{\mathrm{s}}\right)-D_{\mathrm{s}} \frac{R}{E_{\mathrm{R}}}
\end{aligned}
$$

Different types of water flooding oilfield within same development stage, water storage percentage mainly reflect oil-water viscosity ratio factors. Oil-water viscosity ratio is bigger, water storage percentage the smaller. On the basis of referring to the number of oilfield regressed $D_{s}$, the formula of between $A_{s}$ and oil-water viscosity ratio $\mu_{R}$ in the regression statistics, oil-water viscosity ratio range from 2.5 to 200.0. The total is 35 , and correlation coefficient were 0.9992 and 0.9968 .

The result:

tallied the results:

$$
\begin{aligned}
& D_{\mathrm{s}}=\frac{6.689}{\ln \mu_{\mathrm{R}}+0.186} \\
& A_{\mathrm{s}}=\frac{5.854}{0.0476-\ln \mu_{\mathrm{R}}}
\end{aligned}
$$

$$
E_{\mathrm{s}}=1-\mathrm{e}^{\left(A_{\mathrm{s}}+D_{\mathrm{s}} \frac{R}{E_{\mathrm{R}}}\right)}
$$

Empirical formula of $E_{S}-R$ relation curve is formula of 21, reserves utilization level range from 0.15 to 0.85 . It can be seen from formula 21 that the water storage percentage biggest and water flooding recovery factor higher, effect development the better. Otherwise, effect development is worse on the same type of oilfield and in a degree of reserve recovery factor.

According to oil-water viscosity ratio which evaluates effect water injection. Bringing the value of $A_{s}$ and $D_{s}$ which computed formula 13 and 14 into equation of 15, in other words, the curve of between water storage percentage and degree of reserve recovery factor were calculated and drawn in different water flooding recovery factor. After calculated water flooding recovery factor applicants several kinds of methods, and drawn curve of $\mathrm{E}_{\mathrm{s}}-\mathrm{R}$ as a standard curve. It makes comparison analysis that between $\mathrm{E}_{\mathrm{s}}-\mathrm{R}$ curve and practical curve. Index and trend of water storage percentage can be evaluated. Potential water flooding recovery can be predicted under the condition of production.

Evaluation by following steps: 14.

(1) The value of As and $D_{s}$ are calculated by evaluate oil-water viscosity ratio, formula 13 and

(2) A number assigns to $E_{s}-R$, the curve of between water storage percentage and degree of reserve recovery factor and formula 15 was calculated and drawn.

(3) It makes comparison analysis that between $\mathrm{E}_{\mathrm{s}}-\mathrm{R}$ curve and practical curve, and evaluates effect of water flooding.

$$
\begin{gathered}
D_{\mathrm{s}}=\frac{6.689}{\ln \mu_{\mathrm{R}}+0.186}=\frac{6.689}{\ln 15+0.186}=2.3113 \\
A_{\mathrm{s}}=\frac{5.854}{0.0476-\ln \mu_{\mathrm{R}}}=\frac{5.584}{0.0476-\ln 15}=-2.2
\end{gathered}
$$

Water storage percentage under a condition of water flooding recovery factor corresponding degree of reserve recovery factor can be calculated by formula 15 . The calculation results listed in the table. This is the curve of $\mathrm{E}_{\mathrm{s}} \mathrm{R}$. When the value of water flooding recovery factor is $35 \%$, which is a standard curve. 


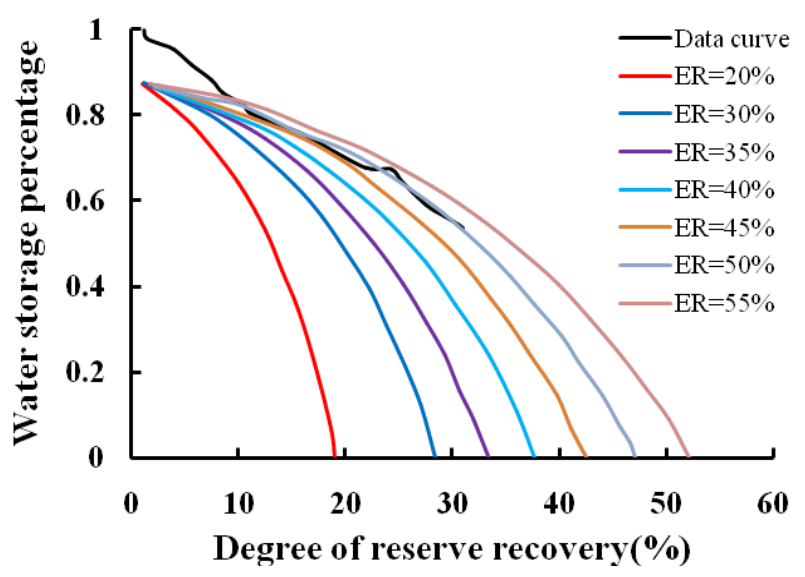

Fig.9 Curve of between water storage percentage and degree of reserve recovery factor for Beierxi

It can be seen from figure 9 that low degree of reserve recovery factor and water storage percentage greatly decline in the initial stage of reservoir development. When degree of reserve recovery factor reached around $10 \%$ and water storage percentage slowly decline, development efficiency is better. Water flooding recovery factor is predicted which reached $50 \%$.

Table 2 The result summary sheet of recovery factor at Beierxi area

\begin{tabular}{c|c|c}
\hline $\begin{array}{c}\text { Water flooding characteristic } \\
\text { curve }(\%)\end{array}$ & $\begin{array}{c}\text { Water storage percentage } \\
\text { theoretical chart method } \\
(\%)\end{array}$ & $\begin{array}{c}\text { Average ultimate } \\
\text { recovery factor }(\%)\end{array}$ \\
\hline 47.93 & 50 & 48.97 \\
\hline
\end{tabular}

Practical may reach recoverable reserves which take advantage of type water flooding curve and relationship curve of between water storage percentage and degree of reserve recovery factor can predict at Beierxi area on the condition of existing technologies and work regulations currently. The results are predicted which shows that water flooding recovery factor is $48.97 \%$ at Beierxi area.

\section{Conclusions}

The main achievement of evaluating efficiency of oilfield for Beierxi is as follows:

1. Infill series of strata has some shortcomings that each perforated interval is long, contradiction of inter layer is big and production degree of poor reservoirs are poor at Beierxi. The oilfield has eight sets of well pattern. Oilfield for Beierxi have 5 sets of flooding pattern among bed set well pattern, Sa area has a basic well pattern, P II area has a high reservoir, Sa area has two poor reservoirs, P II area has a high poor reservoir and three times encryption well pattern. Well pattern has their own characteristics that bed set well pattern is enough, and mining object is complicated, and bed set well pattern is cut across each other, and product contradiction of reservoir classification is comparatively and intense adjustment is not strong because of complicated relationship of bed set well pattern at high water-cut stage.

2. The effect of increase production has no obvious by three times encryption well pattern. To increase production that the feasibility of encryption well pattern is poor. The restructuring of flooding pattern which can is considered to increase production.

3. At present, general water rate reached $92.35 \%$ at high water-cut stage on Beierxi area. The highest value water rate of basic well pattern reached $94.19 \%$. The lowest value water rate of three times encryption well pattern reached $87.02 \%$.

4. The type of oil production rate is decreasing rapidly, and it needs to constantly adjust to increase production on Beierxi area.

5. Due to water flooding characteristic curve and chart method of theories water storage percentage which evaluates water flooding recovery factor on Beierxi area. Water flooding recovery factor reached $48.97 \%$, and withdrawal degree of flooding pattern reached $43.13 \%$. 


\section{Acknowledgement}

This work is supported by Northeast Petroleum University Innovation Foundation For Postgraduate(No. YJSCX2016-014NEPU).

\section{References}

[1] Guthrie R K, Gerenbegrer M H. The use of multiple correlation analysis for interpreting petroleum engineering data[C]. Drilling and Production Practice, API,1955:130-137.

[2] F.F. Wright. Field results indicate significant advances in water-flooding. JPT(OCT, 1958) pp12.

[3] M. Parts, C. S. Matthews. Prediction of injection rate and production history for multi-fluid five-spot floods. JPT(May,1959) pp98.

[4] Zhang Rui. A method of evaluation for the prediction of effect of water flooding. Petroleum Expoloration and Development, 1985,04:36-42.

[5]Zan lixin. A method of determination the rate of water storage and index of water displacement curves of a water flooded reservoir[J]. Petroleum Expoloration and Development, 1987, 03:74-79

[6] Yu Qitai. Decline curve analysis for a water drive reservoir[J]. Petroleum Expoloration and Development, 1993, 04:72-80.

[7] Lemouzy P M, Eschard R, Beucher H. An integrated approach EOR evaluation of production scenarios in the field delineation phase[R]. SPE 22906, 1991.

[8] Jones A D W, Al-Qabandi S, Reddick C E, et al. Rapid assessment of pattern water flooding uncertainty in a giant oil reservoir[R]. SPE 38890, 1997.

[9] Dunn M D, Chukwu G A. Simulation based dimensionless type curves for predicting waterflood recovery [R]. SPE 68839, 2001.

[10]Wang Guoxian, Xie Jianyong, Fan Jie, et al. Applying instantaneous water cut-recovery percent ratio to evaluate efficiency oilfield development by water flooding[J]. Xinjiang Petroleum Geology, 2002, 23(3):239-241.

[11]Wang Wenhuan. A novel evaluating method for oilfield development effects[J]. Petroleum Drilling Techniques, 2004, 32(6):56-57.

[12]Feng Qihong, Lu Aimin, Yu Hongjun, et al. A new method for evaluating water flooding development effectiveness[J]. Journal of the University of Petroleum,China, 2004, 28(2):58-60.

[13]Zhang Jinqing, Sun Fujie, An Guirong. Study on incremental law of water cut and decline law in water drive oilfield[J]. Petroleum Geology and Recovery. 2011, 06:82-85+116.

[14] Yan Qinghui, Liu Weidong, Xiao Hanmin, et al. Study on the adaptation of water drive curves.

[15]Wang Xiaolin, Yu Lijun, Li Zhiping, et al. New water-flooding characteristic curves at the stage of extra-high water cut[J]. Petroleum Geology and Oilfield Development in Daqing. 2015, 06:54-56. 